\title{
Study of Natural Rubber Latex Reactions
}

The Health Industry Manufacturers Association (HIMA) and the CDC are collaborating on a study of reactions to latex-containing products. The purpose of this study is to determine the prevalence and type of natural rubber latex reactions among workers at a wide variety of healthcare facilities and natural rubber latex manufacturing plants nationwide.

Reports of adverse reactions to products containing natural rubber latex have been increasing. Reports have been found in the medical literature and in the medical devices error/accident reporting system at the Food and Drug Administration. These reports and other published studies have identified healthcare workers and pediatric patients with myelodysplasia and other congenital malformations as high-risk groups for adverse reactions to products containing natural rubber latex. No such reports have occurred among natural rubber latex manufacturing workers.

Only two nationwide surveys of healthcare workers have been conducted to determine the prevalence of reactions to latexcontaining products. One study by the Association of Operating Room Nurses, in collaboration with the CDC, surveyed operating room nurses (in press), and another surveyed army dentists (Berky ZT, et al. JAMA, 1992;268:2695-2697). However, the prevalence of reactions to products containing natural rubber latex among all types of healthcare workers and among latex manufacturing workers is unknown. In particular, the relative incidence of reactions between these two groups and the incidence and relationship of localized and systemic reactions is unknown.

HIMA and CDC now are soliciting healthcare facilities and organizations for participation in this study. Participants in the

Brief items of interest for the SHEA N ews or N ewsletter may be sent to C. Glen Mayhall, M D, SHEA, N ewsletter Editor, Division of Infectious Diseases, D epartment of $M$ edicine, U niversity of Tennessee, $M$ emphis, 956 Court A ve., M emphis, TN 38163; FAX (901) 528-5854. Copy should be typed, doublespaced, and should not exceed five pages. 